Pacific Journal of Mathematics

PRIMAL CLUSTERS

ed Yalu 


\section{PRIMAL CLUSTERS}

\section{AdIL YAQUB}

In a series of recent publications [Math. $\mathrm{Z}, 66$ (1957), 452-469; Math Z, 62 (1955), 171-188] Foster introduced and studied the theory of a "primal cluster", - a concept which embraces classes of algebras of such diverse nature as the classes of all (i) prime-fields, (ii) " $n$-fields", (iii) basic Post algebras. Here, a primal cluster is essentially a class $\left\{U_{i}\right\}$ of primal (=strictly functionally complete) algebras of the same species such that every finite subset of $\left\{U_{i}\right\}$ is "independent". The concept of independence is essentially a generalization to universal algebras of the Chinese residue Theorem in number theory. Each cluster, $\widetilde{U}$, equationally defines -in terms of the identities jointly satisfied by the various finite subset of $\widetilde{U}$-a class of " $\widetilde{U}$-algebras", and a structure theory for these $\widetilde{U}$-algebras was established by Foster, - a theory which contains well known results for Boolean rings, $p$-rings, and Post algebras. In order to expand the domain of applications of this theory, one should then look for primal clusters. In this paper a permutation, - , of ths residue class ring $R_{n}, \bmod n$, is constructed, such that $\left.\left\{\left(R_{n}, \times,\right\urcorner\right)\right\}$ forms a primal cluster. In Theorem 9, which is the main result of this paper, it is shown that a much more comprehensive (and quite "heterogeneous") class $K$ of algebras nevertheless forms a primal cluster. Indeed, $K$ here is the union of all nonisomorphic algebras in the classes of all (i) residue class rings, (ii) basic Post algebras, and (iii) " $n$-fields". Thus, the primal cluster $K$ furnishes an extension of the primal clusters which were previously given by Foster (loc. cit.).

In a series of recent publications ([1]-[3]) Foster introduced and studied the theory of a "primal cluster", - a concept which embraces classes of algebras of such diverse nature as (i) the class of all primefields, (ii) the class of all " $n$-fields", (iii) the class of all basic Post algebras, and (iv) the union of the primal clusters (ii) and (iii) above. Here, a primal cluster is essentially a class $\left\{U_{i}\right\}$ of universal algebras $U_{i}$ (all of the same species), each is primal (=strictly functionally complete), and such that every finite subset of $\left\{U_{i}\right\}$ is "independent". The concept of independence is essentially a generalization to universal algebras of the Chinese residue Theorem in number theory. Each cluster, $\widetilde{U}$, equationally defines-in terms of the identites jointly satisfied by the various finite subsets of $\widetilde{U}$-a class of " $\widetilde{U}$-algebras", and a structure theory for these $\widetilde{U}$-algebras was established in [1],

Received July 28, 1964, in revised form October 12, 1964. 
-a theory which contains well known results for Boolean rings, $p$-rings, and Post algebras. In order to expand the domain of applications of this theory, we should then always look for primal clusters. Thus, our present object, in part, will be to first establish that the class $\left\{R_{n}\right\}$ of all residue class rings, $\bmod n$, can be converted to a primal cluster (with respect to suitably chosen operations). Indeed, we shall construct a permutation, - of $R_{n}$ such that $\left(R_{n}, \times,{ }^{-}\right)$is a primal algebra (Theorem 7). We will thus obtain a confirmation to an existence theorem proved in [2, pp. 70-81], - a theorem which implies the existence (but does not give the constructability) of such a permutation, In Theorem 9, which is the main result of this paper, we show that a much more comprehensive (and quite "heterogeneous") class $K$ of algebras nevertheless forms a primal cluster. Indeed, $K$ here is the union of all nonisomorphic algebras in the classes of all (i) residue class rings, (ii) basic Post algebras, and (iii) " $n$-fields". Thus, the primal cluster $K$ furnishes an extension of the primal clusters which were previously given by Foster [3; p. 179].

1. Fundamental concepts. In this section, we recall the following basic concepts of [1]. Let $S=\left(n_{1}, n_{2}, \cdots\right)$ be a given finitary species, where the $n_{1}$ are positive integers, and let $o_{1}, o_{2}, \cdots$ denote the primitive operation symbols of $S$. Here, $o_{i}$ is $n_{i}$-ary, $o_{i}=o_{i}\left(\zeta_{1}, \cdots, \zeta_{n_{i}}\right)$. By an expression $\varphi(\zeta, \cdots)$ of species $S$ we mean a primitive composition of one or more indeterminate-symbols $\zeta, \cdots$ via the primitive operations $o_{i}$. As usual, we shall use the same symbols $o_{i}$ to denote the primitive operations of the algebras $U_{1}, U_{2}, \cdots$ when these algebras are of species $S$. We write " $\varphi(\zeta, \cdots)(U)$ " to mean that the $S$-expression $\varphi$ is interpreted in the $S$-algebra $U$. This simply means that the primitive operation symbols are identified with the corresponding primitive operations of $U$, and the indeterminate-symbols $\zeta, \cdots$ are now viewed as indeterminates over $U$. Thus for unrelated $S$-algebras $U_{1}$ and $U_{2}$, $\varphi(\zeta, \cdots)\left(U_{1}\right)$ will in general be quite unrelated to $\varphi(\zeta, \cdots)\left(U_{2}\right)$. " $\phi(\zeta, \cdots)(U)$ " is also called a strict $U$-function. An identity between the strict $U$-functions $f, g$-holding throughout $U$-is called a strict $U$ identity, and is written as $f(\zeta, \cdots)=g(\zeta, \cdots)(U)$. A finite algebra $U$ with more than one element is called primal if every (set-theoretical) mapping of $U \times \cdots \times U$ into $U$ is expressible by a strict $U$-function. Examples of primal algebras are wide spread. Thus, for example, the two-element Boolean algebra, $\left(F_{2}, \times,{ }^{-}\right)\left(\times=\right.$intersection, ${ }^{-}=$complement $)$ was shown in [1] to be primal. Other examples of primal algebras are (see [1]):

(i) The prime-field $\left(F_{p}, \times,{ }^{-}\right), p=$ prime, and where

$$
F_{p}=\{0,1,2, \cdots, p-1\}, \quad \zeta=\zeta+1(\bmod p) .
$$


(ii) The basic Post algebra $\left(P_{n}, \times,{ }^{-}\right), n$ arbitrary. Here, $P_{n}=$ $\left\{0, \rho_{n-2}, \rho_{n-3}, \cdots, p_{1}, 1\right\}, \zeta \times \eta=\min (\zeta, \eta)$, where "min" refers to the above ordering, and where $0^{-}=1,1^{-}=\rho_{1}, \rho_{1}^{-}=\rho_{2}, \cdots, \rho_{n-2}^{-}=0$.

(iii) The " $n$-field" $\left(F_{n}, \times,{ }^{-}\right), n$ arbitrary. Here,

$$
F_{n}=\left\{0,1, \alpha, \alpha^{2}, \cdots, \alpha^{n-2}\right\}, \quad\left(\alpha^{n-1}=1\right),
$$

and where $0 \times \zeta=\zeta \times 0=0\left(\zeta \in F_{n}\right)$. Furthermore, $0^{-}=1,1^{-}=\alpha$, $\alpha^{-}=\alpha^{2}, \cdots,\left(\alpha^{n-2}\right)^{-}=0$. (For further examples, see [1].)

We now procede to define the concept of independence. Let $\left\{U_{i}\right\}=$ $\left\{U_{1}, \cdots, U_{r}\right\}$ be a finite set of algebras of species $S$. We say that $\left\{U_{i}\right\}$ satisfies the Chinese residue condition, or that $\left\{U_{i}\right\}$ is independent, if, corresponding to each set of expressions $\varphi_{1}, \cdots, \varphi_{r}$ of species $S$, there exists a single expression $\Psi$ such that $\Psi=\varphi_{i}\left(U_{i}\right)(i=1, \cdots, r)$.

A primal cluster of species $S$ is simply a class $\widetilde{U}=\left\{\cdots, U_{i}, \cdots\right\}$ of primal algebras, of species $S$, any finite subset of which is independent.

It was shown in [1] that numerous classes of algebras (of rather diverse nature), including those in (i), (ii), (iii) above, form primal clusters.

2. Independence, Let

$$
n=p_{1}^{k_{1}} \cdots p_{t}^{k_{t}} ; p_{1}>\cdots>p_{t},
$$

where $p_{1}, \cdots, p_{t}$ are primes and $k_{1}, \cdots, k_{t}$ are positive integers. We now have the following.

Definition. With $n, p_{1}, \cdots, p_{t}, k_{1}, \cdots, k_{t}$, as above, the residue class ring $R_{n}$ is of type 1 if $k_{1}=1$, and is of type 2 if $k_{1}>1$.

We procede to define a permutation, - , of $R_{n}$. This we do in two stages.

Case 1. If $R_{n}$ is of type 1. In this case, let $\left\{1, \alpha_{1}, \cdots, \alpha_{\sigma}\right\}$ be the set of all positive integers which are relatively prime to $p_{1}$, and which do not exceed $n$, and choose the notation so that $\alpha_{1} \cdots \alpha_{\sigma}=$ $\alpha_{1}(\bmod n)$. Define, - , by the ordering

$$
\begin{aligned}
& :=\operatorname{def}=0,1, p_{1}, 2 p_{1}, \cdots,\left(\frac{n}{p_{1}}-1\right) p_{1}, \alpha_{\sigma}, \alpha_{\sigma-1}, \cdots, \alpha_{1} ; \\
& \text { i.e., } 0^{-}=1,1^{-}=p_{1}, \cdots, \alpha_{1}^{-}=0 .
\end{aligned}
$$

REMARK. If $n$ is prime, the $\left[p_{1}, \cdots,\left\{\left(n / p_{1}\right)-1\right\} p_{1}\right]$ is empty. If $n=2$, then both $\left[p_{1}, \cdots,\left\{\left(n / p_{1}\right)-1\right\} p_{1}\right]$ and $\left\{\alpha_{\sigma}, \cdots, \alpha_{1}\right\}$ are empty.

Case 2. If $R_{n}$ is of type 2. Then $n=p_{1}^{k_{1}} \cdots p_{t}^{k_{t}}$, and where $k_{1} \geqq 2$. Let $\varphi(m)$ denote the familiar Euler $\varphi$-function (=number of positive integers $\leqq m$ and relatively prime to $m$ ). Then 


$$
\varphi\left(p_{1}^{k_{1}-1}\right)=p_{1}^{k_{1}-1}-p_{1}^{k_{1}-2} \geqq p_{1}^{k_{1}-2} \geqq 2^{k_{1}-2} \geqq k_{1}-1 .
$$

Let $\left\{\mu_{1}(=1), \mu_{2}, \cdots, \mu_{k_{1}-1}\right\}$ be an arbitrary but fixed set of distinct positive integers, each relatively prime to $p_{1}$ and each less than $p_{1}^{k_{1}-1}$. This is possible by $(2.1)^{\prime}$. Moreover, let $\left\{1, \eta_{2}, \cdots, \eta_{s}\right\}$ be the set of all positive integers which are relatively prime to $p_{1}$ and which are less than $n$. Now, define, , by the following ordering:

(2.2) If $n=4,^{-}:=\operatorname{def}=0,1,3,2$.

(2.3) If $n \neq 4, \stackrel{\sim}{:}=\operatorname{def}=0,1, \eta_{2}, \cdots, \eta_{s}, p_{1}, \mu_{2} p_{1}, \cdots, \mu_{k_{1-1}} p_{1}, \beta_{1} p_{1}, \cdots$, $\beta_{v} p_{1}$ where $\beta_{v} p_{1}=\operatorname{def}=\left(1 \cdot \eta_{2} \cdots \eta_{s}\right)\left\{\left(p_{1}\right)\left(\mu_{2} p_{1}\right) \cdots\left(\mu_{k_{1}-1} p_{1}\right)\right\}(\bmod n)$.

Here, the (possibly empty) set $\left\{\beta_{1} p_{1}, \cdots, \beta_{v-1} p_{1}\right\}$ gives the remaining elements of $R_{n}$, arranged in an arbitrary but fixed way.

Lemma 1. Suppose that $R_{n}$ is of type $2, n \neq 4$, and suppose that, -, satisfies (2.3). Then $\beta_{v} p_{1}$ is distinct from $0,1, \eta_{2}, \cdots, \eta_{s}$, $p_{1}, \cdots, \mu_{k_{1-1}} p_{1}$, and, - , is a permutation of $R_{n}$.

Proof. Clearly, $\beta_{v} p_{1} \neq 0$. Furthermore, $\beta_{v} p_{1} \neq 1, \eta_{2}, \cdots, \eta_{s}$. If $k_{1}>2$, then $\beta_{v} p_{1}=\lambda p_{1}^{2}$, for some $\lambda$, and the result follows since all of the $\eta_{i}$ and $\mu_{j}$ are relatively prime to $p_{1}$. Hence assume $k_{1}=2$ (recall that $k_{1}>1$ since $R_{n}$ is of type 2.) Now, assume that $n=p_{1}^{k_{1}} \cdots p_{t}^{k_{t}}$, and $t>1$. Then $p_{2} \in\left\{\eta_{2}, \cdots, \eta_{s}\right\}$, and hence $\beta_{v} p_{1}=\lambda p_{1} p_{2}$, for some $\lambda$. Again, the result follows since $\left\{p_{1}, \cdots, \mu_{k_{1}-1} p_{1}\right\}=\left\{p_{1}\right\}$. An easy application of Wilson's Theorem shows that, in this case,

$$
1 \cdot \eta_{2} \cdots \eta_{s} \equiv(-1)^{p_{1}}\left(\bmod p_{1}\right), \quad\left(s=\varphi\left(p_{1}^{2}\right)=p_{1}^{2}-p_{1}\right),
$$

and hence $\beta_{v} p_{1} \equiv(-1)^{p_{1}} p_{1}\left(\bmod p_{1}^{2}\right) \not \equiv p_{1}\left(\bmod p_{1}^{2}\right)$ unless $p_{1}=2$ (and hence $\left.n=p_{1}^{2}=4\right)$. Hence, if $n \neq 4, \beta_{v} p_{1}$ is distinct from $p_{1}$, and the lemma is proved.

Following [1], we define a frame to be an algebra $\left(U, \times,{ }^{-} ; 0,1\right)$ of species $(2,1)$ possessing distinguished elements $0,1(0 \neq 1)$ such that

$$
0 \times \zeta=\zeta \times 0=0,1 \times \zeta=\zeta \times 1=\zeta \quad(\zeta \in U),
$$

and where $\zeta^{-}$is a cyclic permutation of the elements of $U$ such that $0^{-}=1$.

Now, let, `, denote the inverse of, ${ }^{-}$, and as in [1], define

$$
a \times \_b=\left(a^{-} \times b^{-}\right)^{-} \text {. }
$$

It is readily verified that $a \times, 0=0 \times, a=a$.

We shall now state the following result of $[1, p .456]$ which is very useful in proving the independence of algebras. 
LEMma 2. Let $U_{1}, U_{2}, \cdots, U_{r}$ be a set of frames,

$$
U_{i}=\left(U_{i}, \times, \frown ; 0_{i}, 1_{i}\right) \text {. }
$$

If there exist $\left(\begin{array}{l}r \\ 2\end{array}\right)$ expressions $\left.\right|_{i j}$ such that $\left.\right|_{i j}=\left\{\begin{array}{l}1_{i}\left(U_{i}\right) \\ 0_{j}\left(U_{j}\right)\end{array}(1 \leqq i<j \leqq r)\right.$, then the algebras $U_{1}, \cdots, U_{r}$ are independent.

Proof. The proof is essentially a combination of the proofs of Lemma 5.1 and Theorem 5.2 of [1]. Indeed, if $\left.\right|_{i j}$ is as above, then by defining

$$
l_{i j}^{\prime}=\operatorname{def}=\left[\left.\right|_{i j}\left\{\left(\left(\left.\right|_{i j}\right)^{\smile}\right)^{-}\right\}\right]^{-},
$$

one readily verifies that

$$
l_{i j}^{\prime}=\left\{\begin{array}{l}
0_{i}\left(U_{i}\right) \\
1_{j}\left(U_{j}\right)
\end{array} .\right.
$$

Hence, there exist expressions $\left.\right|_{i j}$ such that $\left.\right|_{i j}=\left\{\begin{array}{l}1_{i}\left(U_{i}\right) \\ 0_{j}\left(U_{j}\right)\end{array}(i \neq j ; i, j=\right.$ $1, \cdots, r)$. Now, for each $i=1, \cdots, r$, define

$$
\left.\right|_{i}(\zeta)=\operatorname{def}=\left.\left.\left.\right|_{i 1}(\zeta) \cdot\right|_{i 2}(\zeta) \cdots\right|_{i r}(\zeta)\left(\text { no }\left.\right|_{i i} \text { term }\right) .
$$

It is easily verified that $\left.\right|_{i}(\zeta)=\left\{\begin{array}{l}1_{i}\left(U_{i}\right) \\ 0_{j}\left(U_{j}\right)\end{array}\right.$, for all $j \neq i$. Now, to prove the independence of $U_{1}, \cdots, U_{r}$, let $\varphi_{1}(\zeta, \cdots), \cdots, \varphi_{r}(\zeta, \cdots)$ be any set of expressions of species $\times, \sim$, and define

$$
\Psi(\zeta, \cdots)=\left\{\varphi_{1}(\zeta, \cdots) \times\left.\right|_{1}(\zeta)\right\} \times{ }_{-} \cdots \times{ }_{-}\left\{\varphi_{r}(\zeta, \cdots) \times\left.\right|_{r}(\zeta)\right\} .
$$

Then it is easily seen that $\Psi(\zeta, \cdots)=\varphi_{i}(\zeta, \cdots)\left(U_{i}\right), i=1, \cdots, r$, and the lemma is proved.

Suppose $n=p_{1}^{k_{1}} \cdots p_{t}^{k_{t}}, p_{1}>\cdots>p_{t}$, where each $p_{i}$ is prime and where each $k_{j}$ is a positive integer. Suppose that

$$
r_{n}=\operatorname{def}=n-\frac{n}{p_{1}}+k_{1} .
$$

It is readily verified that $2 \leqq r_{n} \leqq n$, for all $n \geqq 2$. We now have the following.

Lemma 3. Let $n, p_{1}, \cdots, p_{t}, k_{1}, \cdots, k_{t}$ be as above. Then

$$
n-\frac{n}{p_{1}}+k_{1}>n-\frac{n}{p_{i}}+k_{i}
$$

for each $i=2, \cdots, t$.

Proof. Let 


$$
d=\left(n-\frac{n}{p_{1}}+k_{1}\right)-\left(n-\frac{n}{p_{i}}+k_{i}\right), \quad(i \neq 1) .
$$

Then,

$$
d=\frac{n\left(p_{1}-p_{i}\right)}{p_{1} p_{i}}+k_{1}-k_{i} \geqq \frac{n}{p_{1} p_{i}}+\left(k_{1}-k_{i}\right) .
$$

If $k_{1}-k_{i} \geqq 0$, then, clearly, we are through. Assume $k_{1}<k_{i}$. Then, $k_{i} \geqq 2$. Hence,

$$
\begin{aligned}
d & \geqq \frac{n}{p_{1} p_{i}}-\left(k_{i}-k_{1}\right) \geqq p_{1}^{k_{1}-1} p_{i}^{k_{i}-1}-\left(k_{i}-1\right) \\
& \geqq p_{i}^{k_{i}-1}-\left(k_{i}-1\right) \geqq 2^{k_{i-1}}-\left(k_{i}-1\right)>0,
\end{aligned}
$$

and the lemma is proved.

CoRollary 4. Any subset of $\left\{n-\left(n / p_{1}\right)+k_{1}-1\right\}$ distinct elements taken from $\{0,1,2, \cdots, n-1\}$ contains at least $k_{i}$ multiples of the prime $p_{i}(i=2, \cdots, t)$.

Proof. This follows readily from Lemma 3.

Again, we shall denote the elements comprising the residue class ring, $\bmod n$, by $R_{n}$. We now have the following.

THEOREM 5. Let $n_{1}, \cdots, n_{t}$ be any set of $t$ distinct positive integers, each $n_{i}>1$, and let, - , be defined as in (2.1) if $R_{n_{i}}$ is of type 1 and as in (2.2), (2.3) if $R_{n_{i}}$ is of type $2(i=1, \cdots, t)$. Then the algebras $\left(R_{n_{1}}, \times,-\right), \cdots,\left(R_{n_{t}}, \times,-\right)$ are independent.

Proof. In view of Lemma 2, and its proof, we will be through if we can prove the existence of the expressions $\left.\right|_{i j}$ of Lemma 2. We shall construct these expressions in several stages. To simplify the notation, denote by $\left(R_{n}, \times,{ }^{-}\right)$any $\left(R_{n^{\prime}}, \times,{ }^{-}\right)$any two distinct algebras in the above set, and define

$$
E=\zeta \zeta^{-} \zeta^{-2} \cdots \zeta^{-n n^{\prime}-1}, \text { where } \zeta^{-k}=\left(\cdots\left((\xi)^{-}\right)^{-} \cdots\right)^{-},
$$

$k$-iterations.

Case 1. $R_{n}$ and $R_{n^{\prime}}$ are both of type 1. Let $r_{n}$ and $r_{n^{\prime}}$ be defined as in (2.4). We now distinguish the following subcases.

Case 1(a). $\quad r_{n^{\prime}}<r_{n}$. By (2.4), (2.5), (2.1), and Corollary 4, it is easily seen that 


$$
\left\{\left(E^{\smile} E^{-2} \cdots E^{r_{n}-2}\right)\left(E^{-n-1}\right)\right\}^{\smile}=\left\{\begin{array}{l}
0\left(R_{n}\right) \\
1\left(R_{n^{\prime}}\right) .
\end{array}\right.
$$

Case 1(b). $\quad r_{n}<r_{n^{\prime}}$. By symmetry, this is essentially the same as Case 1(a).

Case 1(c). $\quad r_{n}=r_{n^{\prime}}$. Since $n \neq n^{\prime}$, assume, without any loss in generality, that $n^{\prime}<n$. We distinguish two subcases.

(i) If $n^{\prime} \nmid n$. It is readily verified that

$$
\left\{\left(E^{\smile^{n+1}} E^{\smile^{n+2}} \cdots E^{\smile_{n+r_{n}-2}}\right)\left(E^{\smile^{n-1}}\right)\right\}^{-}=\left\{\begin{array}{l}
0\left(R_{n}\right) \\
1\left(R_{n^{\prime}}\right) .
\end{array}\right.
$$

(ii) If $n^{\prime} \mid n$. Then, one easily verifies that

$$
\left\{\left(E^{\sim^{\prime}+1} E^{\sim^{\prime}+2} \cdots E^{\sim^{\prime}+r_{n^{\prime}-2}}\right)\left(E^{\sim^{\prime}-1}\right)\right\}^{-}=\left\{\begin{array}{l}
1\left(R_{n}\right) \\
0\left(R_{n^{\prime}}\right) .
\end{array}\right.
$$

Case 2. $R_{n}$ and $R_{n^{\prime}}$ are both of type 2. The argument here is quite similar to the one given in Case 1 . One need only replace in the above proof $\left(E^{\smile} E^{-2} \cdots E^{-r_{n}-2}\right)\left(E^{-n-1}\right)$ by $E^{-} E^{-2} \cdots E^{-r_{n}-1}$ (see (2.4), (2.3), (2.2), and Corollary 4); $\left(E^{-n+1} \cdots E^{-n+r_{n}-2}\right)\left(E^{-n-1}\right)$ by $\left(E^{-n+1} \cdots E^{-n+r_{n}-1}\right)$, etc.

Case 3. $R_{n}$ and $R_{n^{\prime}}$ are of opposite types. Assume, without loss of generality, that $R_{n}$ is of type 1 and $R_{n}$, is of type 2 . We distinguish three subcases.

Case 3(a). $n$ is prime. Since $R_{n^{\prime}}$ is of type 2, therefore, by (2.1), (2.2), (2.3), (2.5), and Corollary $4,\left(E^{-}\right)^{2}=\left\{\begin{array}{l}0\left(R_{n^{\prime}}\right) \\ 1\left(R_{n}\right) \text {. }\end{array}\right.$

Case 3(b). $n$ not prime, $n^{\prime}=4$. Then by (2.1), (2.2), and Corollary 4, $\left(E^{-} E^{-2}\right)^{-}=\left\{\begin{array}{l}0\left(R_{n^{\prime}}\right) \\ 1\left(R_{n}\right) \text {. }\end{array}\right.$

Case 3(c). $n$ not prime, $n^{\prime} \neq 4$. Then by (2.1), (2.3), and Corollary 4,

$$
\left\{\left(E^{\smile} E^{-2} \cdots E^{-n-2}\right)\left(E^{-r_{n}-2}\right)\right\}^{-}=\left\{\begin{array}{l}
0\left(R_{n}\right) \\
1\left(R_{n}{ }^{\prime}\right) .
\end{array}\right.
$$

(Observe that, since, in addition, $R_{n}$ is of type 1, therefore, using (2.4), $r_{n} \geqq 4$ ). The proof of Theorem 5 is now completed upon using Lemma 2 .

3. Primal clusters; principal theorem. In this section, we shall 
prove, among other things, that the residue class frames $\left(R_{n}, \times,{ }^{-}\right)$are primal algebras, where, - , satisfies (2.1) if $R_{n}$ is of type 1, and satisfies (2.2)-(2.3) if $R_{n}$ is of type 2. First, we recall the following result which is an immediate consequence of [2; Theorem 3].

Lemma 6. Let $(U, \times,-)$ be a finite frame, and let $\Delta(\zeta)=0$ if $\zeta=0$ and $\Delta(\zeta)=1$ if $\zeta \neq 0(\zeta \in U)$. Suppose that $\Delta(\zeta)$ is expressible as a strict $U$-function. Then $\left(U, \times,{ }^{-}\right)$is primal.

We now have the following

THEOREM 7. The residue class algebra $\left(R_{n}, \times,-\right)$, where, ${ }^{-}$, is as in (2.1)-(2.3), is primal.

Proof. Case 1. $R_{n}$ is of type 1. In this case, it is readily verified, by (2.1), (2.4) and Corollary 4, that

$$
\Delta(\zeta)=\left\{\left(\zeta^{-} \zeta^{-2} \cdots \zeta^{r_{n-2}}\right)\left(\zeta^{n-1}\right)\right\}^{-} .
$$

The result now follows readily from Lemma 6 .

Case 2. $R_{n}$ is of type 2. In this case, it is easily seen, by (2.2), (2.3), (2.4), and Corollary 4, that

$$
\Delta(\zeta)=\left(\zeta^{-} \zeta^{-2} \zeta^{-3} \cdots \zeta^{-r_{n}-1}\right)^{-} .
$$

Again, the result follows from Lemma 6, and the theorem is proved.

Now, an easy combination of Theorem 7, Theorem 5, and the definition of primal cluster gives the following

THeOREM 8. The residue class algebras $\left\{R_{2}, R_{3}, R_{4}, \cdots, R_{n}, \cdots\right\}$, where $R_{i}=\left(R_{i}, \times,{ }^{-}\right)$and where, ${ }^{-}$, is determined by (2.1)-(2.3), form a primal cluster.

It was proved in [ $3 ; \mathrm{p} .179]$ that the class consisting of $F_{2}, P_{3}, F_{3}$, $P_{4}, F_{4}, \cdots$, where $F_{n}$ and $P_{n}$ denote the $n$-field and basic Post algebra, respectively, (see examples (ii), (iii), Section 1) forms a primal cluster. We shall now prove the following

Theorem 9. Principal Theorem. The class

$$
\left\{F_{q}\right\}_{q \geqq 4} \cup\left\{P_{m}\right\}_{m \geqq 3} \cup\left\{R_{n}\right\}_{n \geqq 2}
$$

is a primal cluster with respect to the above operations.

Proof. First, we recall that the primitive operations of the algebras 
under consideration have been given in examples (ii), (iii), $\S 1$, and in (2.1)-(2.3). Now, in view of the remarks immediately preceding Theorem 9, together with Theorem 8, Lemma 2, and the definition of a primal cluster, we will be through if we can show that: $(A)\left(R_{n}, \times,{ }^{-}\right)$, and $\left(P_{n^{\prime}}, \times,{ }^{-}\right)$, if nonisomorphic, are independent, and $(B)\left(R_{n}, \times,{ }^{-}\right)$ and $\left(F_{n^{\prime}}, \times,{ }^{-}\right)$, if nonisomorphic, are independent.

Proof of (A). First, $R_{n}$ and $P_{n^{\prime}}$ are isomorphic if and only if $n=n^{\prime}=2$. Assume then that $n \geqq 2$ and $n^{\prime} \geqq 3$. We now distinguish the following cases.

Case A1. $n=p \neq 2 ; p$, prime. Then it is easily verified, by (2.5) and Fermat's little Theorem, that

$$
\left(\left(\left(E^{\smile}\right)^{n-1}\right)^{-}\right)^{n-1}=\left\{\begin{array}{l}
1\left(R_{n}\right) \\
0\left(P_{n^{\prime}}\right) .
\end{array}\right.
$$

Case A2. $n=2$. Then, $n^{\prime} \neq 2$. Clearly

$$
\left(E^{\smile} E^{-2}\right)^{-}=\left\{\begin{array}{l}
1\left(R_{n}\right) \\
0\left(P_{n^{\prime}}\right)
\end{array}\right. \text {. }
$$

Case A3. $n$ not prime, $R_{n}$ of type 1 . Then

$$
\begin{gathered}
\left(E^{\smile} E^{-2}\right)^{-}=\left\{\begin{array}{l}
0\left(P_{n^{\prime}}\right) \\
1\left(R_{n}\right)
\end{array} \quad\left(n^{\prime} \neq 2\right),\right. \\
\left\{\left(E^{\smile} E^{-2} \cdots E^{-_{n}-2}\right)\left(E^{\sim n-1}\right)\right\}^{-}=\left\{\begin{array}{l}
1\left(P_{n}^{\prime}\right) \\
0\left(R_{n}\right)
\end{array} \quad\left(n^{\prime}=2\right) .\right.
\end{gathered}
$$

Case A4. $n$ not prime, $R_{n}$ of type 2 . Then

$$
\left(\left(E^{\smile}\right)^{n}\right)^{\smile}=\left\{\begin{array}{l}
0\left(P_{n^{\prime}}\right) \\
1\left(R_{n}\right) .
\end{array}\right.
$$

Assertion (A) now readily follows from Lemma 2.

Proof of (B). It is easily seen that $\left(R_{n}, \times,{ }^{-}\right)$and $\left(F_{n^{\prime}}, \times,{ }^{-}\right)$are isomorphic if and only if $n=n^{\prime}=2$ or $n=n^{\prime}=3$ (see example (iii), $\S 1$, and (2.1)). Assume then that $n^{\prime} \geqq 4, n \geqq 2$. We now distinguish the following cases.

Case B1. $n^{\prime}=n=p=$ prime. Then $\left(\left(E^{\smile} E^{-2} \cdots E^{-p-2}\right)^{-}\right)^{p-1}=$ $\left\{\begin{array}{l}1\left(F_{n^{\prime}}\right) \\ 0\left(R_{n}\right)\end{array}\right.$ 
Case B2. $n$ prime, $n^{\prime} \neq n$. Then $\left(E^{\sim} E^{-n}\right)^{n^{\prime}-1}=\left\{\begin{array}{l}0\left(R_{n}\right) \\ 1\left(F_{n^{\prime}}\right) .\end{array}\right.$

Case B3. $n$ not prime, $R_{n}$ of type 1. Then $E^{\sim} E^{-2}=\left\{\begin{array}{l}1\left(F_{n^{\prime}}\right) \\ 0\left(R_{n}\right)\end{array}\right.$.

Case B4. $n$ not prime, $R_{n}$ of type 2. Then $\left(E^{-}\right)^{\left(n^{\prime}-1\right) n}=\left\{\begin{array}{l}1\left(F_{n^{\prime}}\right) \\ 0\left(R_{n}\right) .\end{array}\right.$ Assertion (B) now readily follows from Lemma 2, and the theorem is proved.

\section{REFERENCES}

1. A. L. Foster, The generalized Chinese remainder theorem for universal algebras; subdirect factorization, Math. Z. 66 (1957), 452-469.

2. - An existence theorem for functionally complete universal algebras, Math. Z. 71 (1959), 69-82

3. - The identities of-and unique subdirect factorization with-classes of universal algebras, Math. Z. 62 (1955), 171-188.

4. - On the finiteness of free (universal) algebras, Proc. Amer. Math. Soc. 7 (1956), 1011-1013.

University of California, Santa Barbara 


\section{PACIFIC JOURNAL OF MATHEMATICS}

\section{EDITORS}

\section{H. SAMELSON}

Stanford University

Stanford, California

\section{R. M. BLUMenthaL \\ University of Washington \\ Seattle, Washington 98105}

*J. DugundjI

University of Southern California Los Angeles, California 90007

\section{RICHARD ARENS}

University of California

Los Angeles, California 90024

\section{ASSOCIATE EDITORS}
E. F. BECKENBACH
B. H. NeUManN
F. WOLF
K. YosIDA

\section{SUPPORTING INSTITUTIONS}

\author{
UNIVERSITY OF BRITISH COLUMBIA \\ CALIFORNIA INSTITUTE OF TECHNOLOGY \\ UNIVERSITY OF CALIFORNIA \\ MONTANA STATE UNIVERSITY \\ UNIVERSITY OF NEVADA \\ NEW MEXICO STATE UNIVERSITY \\ OREGON STATE UNIVERSITY \\ UNIVERSITY OF OREGON \\ OSAKA UNIVERSITY \\ UNIVERSITY OF SOUTHERN CALIFORNIA
}

\author{
STANFORD UNIVERSITY \\ UNIVERSITY OF TOKYO \\ UNIVERSITY OF UTAH \\ WASHINGTON STATE UNIVERSITY \\ UNIVERSITY OF WASHINGTON \\ AMERICAN MATHEMATICAL SOCIETY \\ CHEVRON RESEARCH CORPORATION \\ TRW SYSTEMS \\ NAVAL ORDNANCE TEST STATION
}

Mathematical papers intended for publication in the Pacific Journal of Mathematics should be typewritten (double spaced). The first paragraph or two must be capable of being used separately as a synopsis of the entire paper. It should not contain references to the bibliography. Manuscripts may be sent to any one of the four editors. All other communications to the editors should be addressed to the managing editor, Richard Arens at the University of California, Los Angeles, California 90024.

50 reprints per author of each article are furnished free of charge; additional copies may be obtained at cost in multiples of 50 .

The Pacific Journal of Mathematics is published monthly. Effective with Volume 16 the price per volume (3 numbers) is $\$ 8.00$; single issues, $\$ 3.00$. Special price for current issues to individual faculty members of supporting institutions and to individual members of the American Mathematical Society: $\$ 4.00$ per volume; single issues $\$ 1.50$. Back numbers are available.

Subscriptions, orders for back numbers, and changes of address should be sent to Pacific Journal of Mathematics, 103 Highland Boulevard, Berkeley 8, California.

Printed at Kokusai Bunken Insatsusha (International Academic Printing Co., Ltd.), No. 6, 2-chome, Fujimi-cho, Chiyoda-ku, Tokyo, Japan.

PUBLISHED BY PACIFIC JOURNAL OF MATHEMATICS, A NON-PROFIT CORPORATION

The Supporting Institutions listed above contribute to the cost of publication of this Journal, but they are not owners or publishers and have no responsibility for its content or policies.

* Paul A. White, Acting Editor until J. Dugundji returns. 


\section{Pacific Journal of Mathematics}

\section{Vol. 16, No. 2 December, 1966}

Loren N. Argabright, Invariant means on topological semigroups ........ 193

William Arveson, A theorem on the action of abelian unitary groups ...... 205

John Spurgeon Bradley, Adjoint quasi-differential operators of Euler

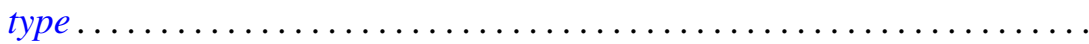

Don Deckard and Lincoln Kearney Durst, Unique factorization in power series rings and semigroups ........................... 239

Allen Devinatz, The deficiency index of ordinary self-adjoint differential operators..................................... 243

Robert E. Edwards, Operators commuting with translations ............ 259

Avner Friedman, Differentiability of solutions of ordinary differential equations in Hilbert space .............................. 267

Boris Garfinkel and Gregory Thomas McAllister, Jr., Singularities in a variational problem with an inequality ......................

Seymour Ginsburg and Edwin Spanier, Semigroups, Presburger formulas,

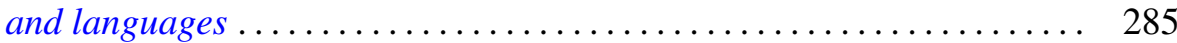

Burrell Washington Helton, Integral equations and product integrals . . . . . . 297

Edgar J. Howard, First and second category Abelian groups with the n-adic topology.........................................

Arthur H. Kruse and Paul William Liebnitz, Jr., An application of a family homotopy extension theorem to ANR spaces.

Albert Marden, I. Richards and Burton Rodin, On the regions bounded by homotopic curves

Willard Miller, Jr., A branching law for the symplectic groups ...

Marc Aristide Rieffel, A characterization of the group algebras of the finite

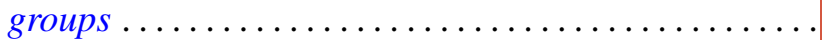

P. P. Saworotnow, On two-sided $H^{*}$-algebras

John Griggs Thompson, Factorizations of p-solvable groups ...

Shih-hsiung Tung, Harnack's inequalities on the classical Cartan

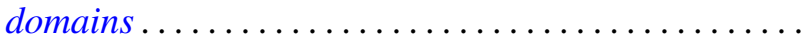

